\title{
No Resistance to Tenofovir Alafenamide Detected through 96 Weeks of Treatment in Patients with Chronic Hepatitis B Infection
} \author{
Kathryn M. Kitrinos, a Anuj Gaggar, a Namiki Izumi,g Young-Suk Lim ${ }^{\text {h }}$ \\ aGilead Sciences, Foster City, California, USA \\ bDepartment of Medicine and Therapeutics, Institute of Digestive Disease and State Key Laboratory of \\ Digestive Disease, The Chinese University of Hong Kong, Hong Kong \\ cService d'Hépatologie, Hôpital Beaujon, Clichy, France \\ dDivision of Gastroenterology and Hepatology, Department of Medicine, NYU Langone Medical Center, NYU \\ School of Medicine, New York, New York, USA \\ eDepartment of Gastroenterology, All India Institute of Medical Sciences, New Delhi, India \\ fHospital Universitari Vall d'Hebron, Barcelona, Spain \\ gDepartment of Gastroenterology and Hepatology, Musashino Red Cross Hospital, Tokyo, Japan \\ nDepartment of Gastroenterology, Asan Medical Center, University of Ulsan College of Medicine, Seoul, South \\ Korea
}

(D) Andrea L. Cathcart, ${ }^{a}$ Henry Lik-Yuen Chan, ${ }^{b}$ Neeru Bhardwaj, ${ }^{a}$ Yang Liu, a Patrick Marcellin,c (D) Calvin Q. Pan, ${ }^{\text {d }}$ Shalimar,e

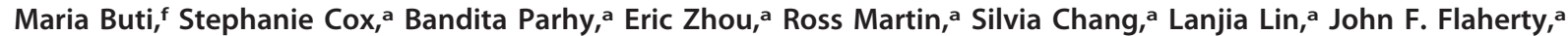

ABSTRACT Tenofovir alafenamide (TAF) has shown equivalent efficacy and improved safety profiles for patients with chronic hepatitis B (CHB) compared to tenofovir disoproxil fumarate (TDF). However, limited data are available for its resistance profiles. In two clinical trials, 1,298 hepatitis $\mathrm{E}$ antigen-positive and -negative patients with $\mathrm{CHB}$ were randomized 2:1 and treated with TAF $(n=866)$ or TDF $(n=432)$. Baseline nucleos(t)ide analog resistance substitutions in HBV polymerase/reverse transcriptase (Pol/RT) were assessed using INNO-LiPA Multi-DR v2/v3. Resistance surveillance was conducted for patients with viremia (HBV DNA $\geq 69 \mathrm{IU} / \mathrm{ml}$ ) by HBV Pol/RT sequencing at week 96 or at discontinuation. In vitro phenotypic analysis was performed for patients with conserved site substitutions or virologic breakthrough while adherent to the study drug. At baseline, the majority of patients harbored virus with wild-type Pol/RT (89.2\%), with $10.8 \%$ harboring resistance associated mutations. A similar percentage of patients in the TAF or TDF groups qualified for sequence analysis through week 96 (TAF, 11.1\%; TDF, $10.9 \%)$. Of these, a small percentage of patients experienced virologic breakthrough (TAF, 2.8\%; TDF, 3.2\%) that was often associated with drug nonadherence (TAF, 30\%; TDF, 50\%). Across treatment groups, 132 patients qualified for sequence analysis through week 96, with nearly half having no sequence changes from baseline (43.2\%). Most sequence changes occurred at polymorphic positions, and no isolates showed a reduction in susceptibility in vitro. After 96 weeks, the proportion of patients achieving virus suppression (HBV DNA $<69 \mathrm{IU} / \mathrm{ml}$ ) was similar across treatment groups, and no substitutions associated with resistance to TAF or TDF were detected. (These studies have been registered at ClinicalTrials.gov under identifiers NCT01940471 and NCT01940341.)

KEYWORDS tenofovir, hepatitis B virus, resistance, tenofovir alafenamide, antiviral agents

$\mathrm{H}^{2}$ epatitis B virus (HBV) infection is a major cause of chronic liver disease with nearly 250 million people chronically infected globally (1). For long-term therapy of diseases such as chronic hepatitis $B(\mathrm{CHB})$, a favorable safety profile, as well as a high
Received 30 May 2018 Accepted 14 June 2018

Accepted manuscript posted online 23 July 2018

Citation Cathcart AL, Chan HL-Y, Bhardwaj N, Liu Y, Marcellin P, Pan CQ, Shalimar, Buti M, Cox S, Parhy B, Zhou E, Martin R, Chang S, Lin L, Flaherty JF, Kitrinos KM, Gaggar A, Izumi N, Lim Y-S. 2018. No resistance to tenofovir alafenamide detected through 96 weeks of treatment in patients with chronic hepatitis B infection. Antimicrob Agents Chemother 62:e01064-18. https://doi.org/10.1128/AAC .01064-18

Copyright $\odot 2018$ American Society for Microbiology. All Rights Reserved.

Address correspondence to Andrea L. Cathcart, andrea.cathcart@gilead.com. 
barrier to the development of resistance, is desirable. Currently, only two classes of drugs are approved for the treatment of $\mathrm{CHB}$, including a finite course of injectable interferon and oral nucleos(t)ide reverse transcriptase inhibitors [N(t)RTIs]. Of these, oral antivirals (OAVs) achieve a higher rate of HBV DNA suppression. First-generation $\mathrm{N}(\mathrm{t}) \mathrm{RT}$ Is such as lamivudine (LAM), adefovir (ADV), and telbivudine result in drug resistance rates ranging from $11 \%$ of patients for ADV to more than $50 \%$ for LAM after 3 years in treatment-naive patients (2-5). Approval of entecavir (ETV) for treatment of $\mathrm{CHB}$ significantly lowered rates of resistance to $<1 \%$ after 2 years in treatment-naive patients; however, resistance to this agent in patients with previous LAM treatment is substantially higher, reaching over $50 \%$ of patients through 6 years of ETV treatment $(6$, 7; for a review, see reference 8). Although multiple HBV N(t)RTIs are available for treatment of $\mathrm{CHB}$, tenofovir disoproxil fumarate (TDF) is the only oral antiviral with no detectable resistance mutations in a clinical setting through up to 8 years of treatment $(9,10)$.

Tenofovir (TFV), the parent drug of TDF, is an inhibitor of both the HBV and HIV-1 reverse transcriptase (RT) (11). The active metabolite of tenofovir, tenofovir-diphosphate, is a competitive inhibitor of both RT enzymes, causing termination of viral DNA elongation during viral replication. While treatment with TDF is efficacious and leads to high rates of HBV DNA suppression, prolonged use can be associated with nephrotoxicity and bone-related toxicity in some patients $(12,13)$. Tenofovir alafenamide (TAF) is a phosphonamidate oral prodrug of TFV for treatment of patients with $\mathrm{CHB}$ (14). TAF is more stable in the plasma compared to TDF, resulting in higher levels of the active metabolite tenofovir-diphosphate to target cells. This allows TAF to be administered at approximately one-tenth the TDF dose, resulting in lower systemic TFV exposures. Clinical trials in HIV- or HBV-infected individuals reported equivalent efficacy and improved safety profiles in both renal and bone toxicity for TAF compared to TDF (15-19).

Two ongoing, global, phase 3 studies comparing TAF to TDF for the treatment of $\mathrm{CHB}$ in treatment naive and experienced hepatitis $\mathrm{E}$ antigen ( $\mathrm{HBeAg}$ )-positive or HBeAg-negative patients found TAF to be noninferior to TDF in the proportion of HBV patients with an HBV DNA level of $<29 \mathrm{IU} / \mathrm{ml}$ at 48 and 96 weeks of treatment (16-18). We summarize here the integrated resistance analyses performed over 96 weeks of these studies.

\section{RESULTS}

Patient disposition. A total of 1,298 patients were enrolled across both studies, with $425 \mathrm{HBeAg}$-negative patients (study 108) and $873 \mathrm{HBeAg}$-positive patients (study 110). Of these, 866 patients were randomized to the TAF treatment group, and 432 patients were randomized to the TDF treatment group. Clinical analysis of responses to treatment for each study was assessed at week 48 and at week 96 and has been previously published (16-18); only virological responses are discussed here. Through week 96, 1,070 of the 1,298 (82.4\%) patients suppressed HBV DNA to below $69 \mathrm{IU} / \mathrm{ml}$, the assay limit for sequencing (716/866 [TAF] and 354/432 [TDF] patients; Fig. 1), with an additional 58 patients having discontinued early with HBV DNA less than $69 \mathrm{lU} / \mathrm{ml}$ (39/866 [TAF] and 19/432 [TDF] patients). In addition, there were 27 patients who discontinued study treatment before week 24 and therefore did not qualify for virology resistance surveillance (15/866 [TAF] and 12/432 [TDF] patients). A similar proportion of patients in the TAF $(96 / 866,11.1 \%)$ and TDF $(47 / 432,10.9 \%)$ treatment groups had HBV DNA levels of $\geq 69 \mathrm{IU} / \mathrm{ml}$ and were included in the analysis. Of the patients that did not suppress HBV DNA to $<69 \mathrm{IU} / \mathrm{ml}$ at week 96, most (57/96 [TAF] and 25/47 [TDF] patients sequenced) remained viremic in the absence of virologic breakthrough (i.e., persistent viremia). In addition, the majority of patients with HBV DNA levels of $\geq 69 \mathrm{IU} / \mathrm{ml}$ had HBV DNA levels of $>8 \log _{10} \mathrm{IU} / \mathrm{ml}$ (70/96, 72.9\% [TAF] and 29/47, 61.7\% [TDF] patients) at baseline. A small and similar proportion of patients experienced virologic breakthrough between the TAF group (24/866, 2.8\%) and TDF group (14/432, 3.2\%) at week 96. Of these, 7 patients in the TAF group $(7 / 24,29.2 \%)$ and 7 patients in the TDF group 


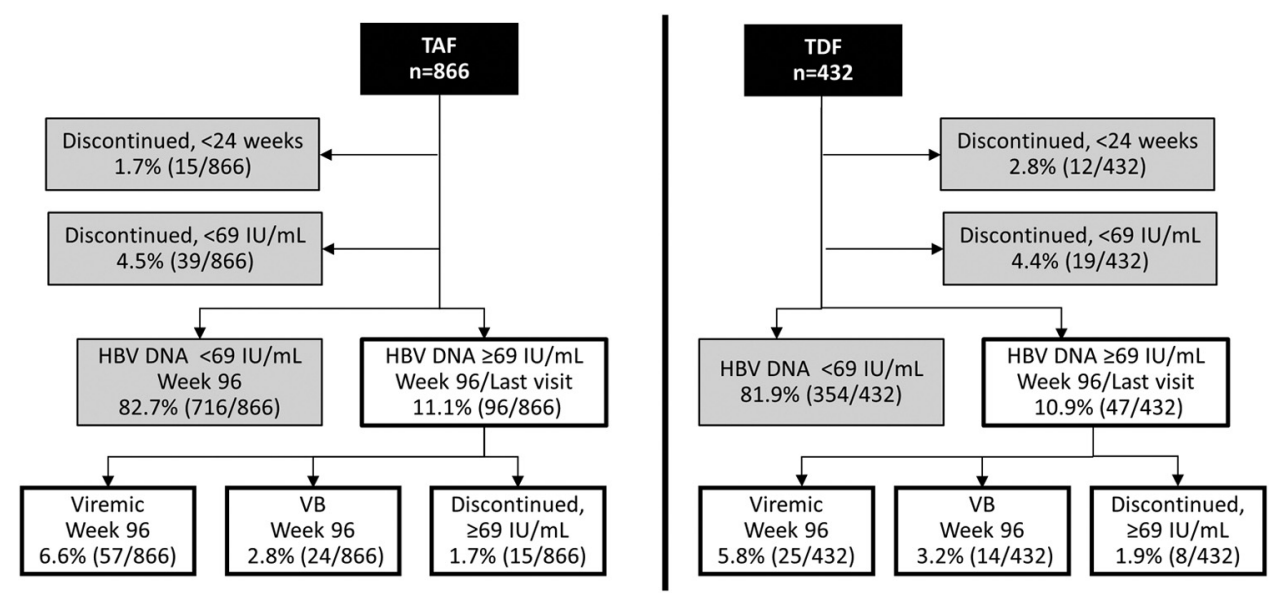

FIG 1 Summary of treatment response at week 96 by treatment group. The percentage of patients for either the TAF (left) or TDF (right) treatment group is depicted for each outcome through week 96 . Patients that missed their week 96 visit but had suppressed HBV DNA at the previous visit were included in the $<69-\mathrm{IU} / \mathrm{ml}$ group. Virologic breakthrough was defined as a confirmed HBV DNA level of $\geq 69 \mathrm{IU} / \mathrm{ml}$ after having $<69 \mathrm{IU} / \mathrm{ml}$ or a $\geq 1.0-\log _{10}$ increase in HBV DNA from nadir. Patients with one visit that met these criteria were classified as viremic in the absence of viral breakthrough.

$(7 / 14,50.0 \%)$ had breakthrough coincident with undetectable tenofovir in the plasma, suggesting nonadherence. Sequence analysis of the 143 patients with HBV DNA levels of $\geq 69 \mathrm{IU} / \mathrm{ml}$ at week 96 or at the last visit from week 24 through week 96 will be discussed below.

Impact of baseline viral genotype and drug resistance mutations on treatment response. The distribution of baseline HBV genotypes was similar between treatment groups, with genotype $C$ being predominant in both groups (TAF, 48.3\%; TDF 46.1\%; Fig. 2A). Seven genotypes were identified at baseline (A to $F$, as well as $H$ ), with low numbers of genotypes $E, F$, and $H$. Although data are limited, previous studies have demonstrated that HBV viral genotype can impact virologic response to OAVs (20). The kinetics of HBV decline and the proportion of patients with HBV DNA levels of $<29$ $\mathrm{IU} / \mathrm{ml}$ through week 96 was evaluated based on the viral genotype (A-D) at baseline (Fig. 2B). Due to the small number of patients enrolled across both studies with genotypes $\mathrm{E}$ to $\mathrm{H}$, the treatment outcomes in these patients were not assessed. Among genotype $A, B, C$, or $D$ patients, similar declines were observed between the TAF and TDF groups regardless of HBV genotype ( $P>0.05$ ); however, the kinetics of viral decline was delayed in patients infected with genotype $D$ in both the TAF and the TDF treatment groups.

All patients were evaluated at baseline for the presence of resistance mutations in the HBV Pol/RT. Mutations that have been demonstrated to confer reduced susceptibility to drug were classified as primary resistance mutations (LAM-R, ADV-R, or ETV-R). Known compensatory mutations or unknown variants at resistance-associated sites were classified as other mutations (21). Patients were evaluated by OAV treatment experience, defined as having at least 12 weeks of prior OAV treatment. A higher percentage of OAV-naive patients (92.1\% TAF, 93.1\% TDF) were classified as wild type compared to OAV-experienced patients (80.7\% TAF, 73.7\% TDF) (Fig. 3A; see also Table $\mathrm{S} 1$ in the supplemental material). Patients harboring other mutations were similar across treatment groups and treatment experience. Primary resistance mutations were observed in $5.4 \%$ of patients overall, with a higher percentage observed in OAVexperienced patients (15.2\% TAF, 21.2\% TDF) compared to OAV-naive patients (1.6\% TAF, 2.4\% TDF). Of the primary resistance mutations detected, LAM-R mutations were most predominant (2.5\% overall, data not shown). Across treatment groups, the percentages of patients with preexisting resistance mutations were similar (TAF 10.5\%, TDF 11.3\%), with the majority of patients harboring wild-type HBV (89.2\% overall). In addition, the distribution of primary resistance mutations and other mutations was 
A

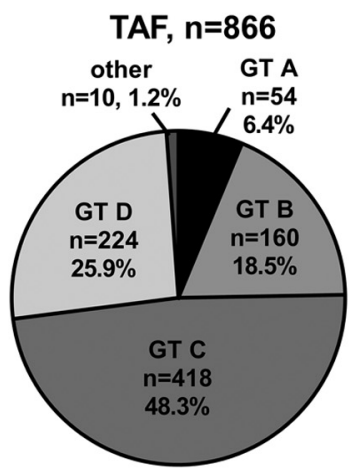

B

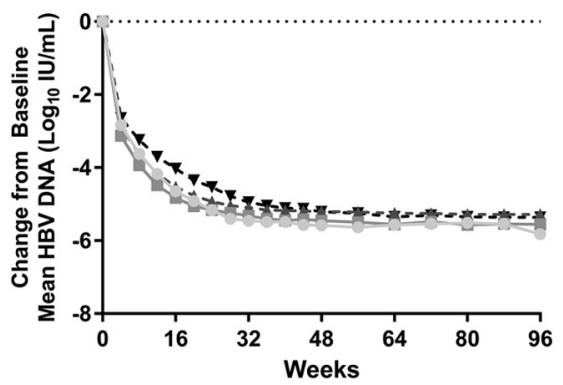

TDF, $\mathrm{n}=432$

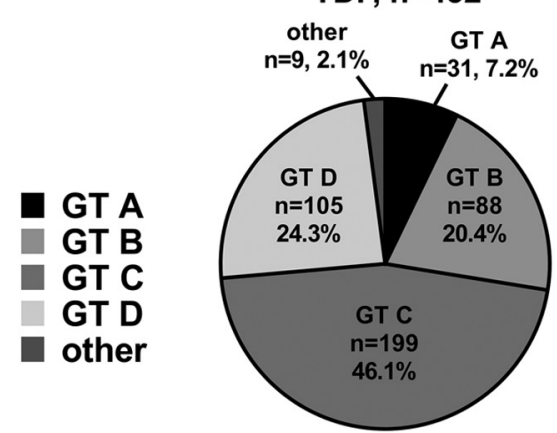

TDF

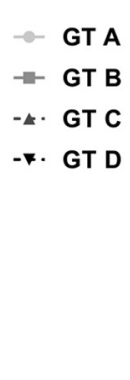

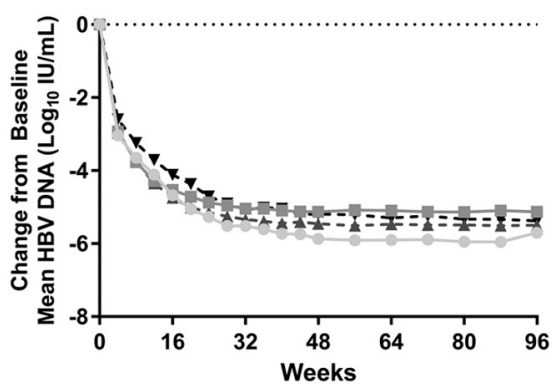

FIG 2 Baseline HBV genotype and impact on treatment outcomes. (A) The percentages of patients in either the TAF (left) or TDF (right) treatment group are graphed by genotype as a percentage of the whole. Patients with genotypes $E, F, H$, or unknown are included as "other." (B) The mean change from the baseline for patients in the TAF (left) or TDF (right) treatment groups is shown for patients with genotypes A through D.

similar between treatment groups (see Table $\mathrm{S} 1$ in the supplemental material; TAF, $4.7 \%$ primary resistance mutations and $5.8 \%$ other mutations; TDF, $6.7 \%$ primary resistance mutations and $4.6 \%$ other mutations).

Analyses were conducted to determine the impact of baseline Pol/RT resistance mutations on treatment outcomes (Fig. 3B). Patients in both the TAF and TDF groups were analyzed by the presence of mutations at baseline, with patients being either wild type, harboring primary resistance-associated Pol/RT mutations, or harboring other mutations. Declines in HBV DNA were similar, with no statistically significant differences between the TAF group compared to the TDF group at week 96 (Fisher exact test, $P>$ 0.05). For both groups, patients with primary resistance mutations had slower kinetics of HBV DNA decline. An additional analysis was conducted to determine whether baseline mutations impacted rates of virologic breakthrough specifically. Similar proportions of patients experienced virologic breakthrough at week 96 between the resistance categories (TAF, $2.7 \%$ wild type, $4.9 \%$ primary resistance mutations, and 0 other mutations; TDF, $2.9 \%$ wild type, 3.4\% primary resistance mutations, and 5.0\% other mutations [data not shown]).

Resistance surveillance. Sequence analysis of the HBV Pol/RT was conducted annually for any patient with an HBV DNA level of $\geq 69 \mathrm{lU} / \mathrm{ml}$ at week 96 or at early study drug discontinuation. Similar proportions of patients qualified for sequence analysis through week 96 between TAF and TDF, with 96 patients from the TAF group and 47 patients from the TDF group being subjected to sequence analysis. Across both treatment groups, the majority of patients had no changes detected in the Pol/RT sequence compared to the baseline, or were unable to be sequenced due to lower levels of virus slightly above the limit for the sequencing assay (55.2\% TAF, 72.3\% TDF, Fig. 4). The majority of the remaining patients had polymorphic site substitutions (35.4\% TAF, 23.4\% TDF), with conserved site substitutions seen in a smaller percentage of patients (9.4\% TAF, 4.3\% TDF). Sequencing results for patients with amino acid changes are listed in Table S2 in the supplemental material. Of the 11 patients with 
A
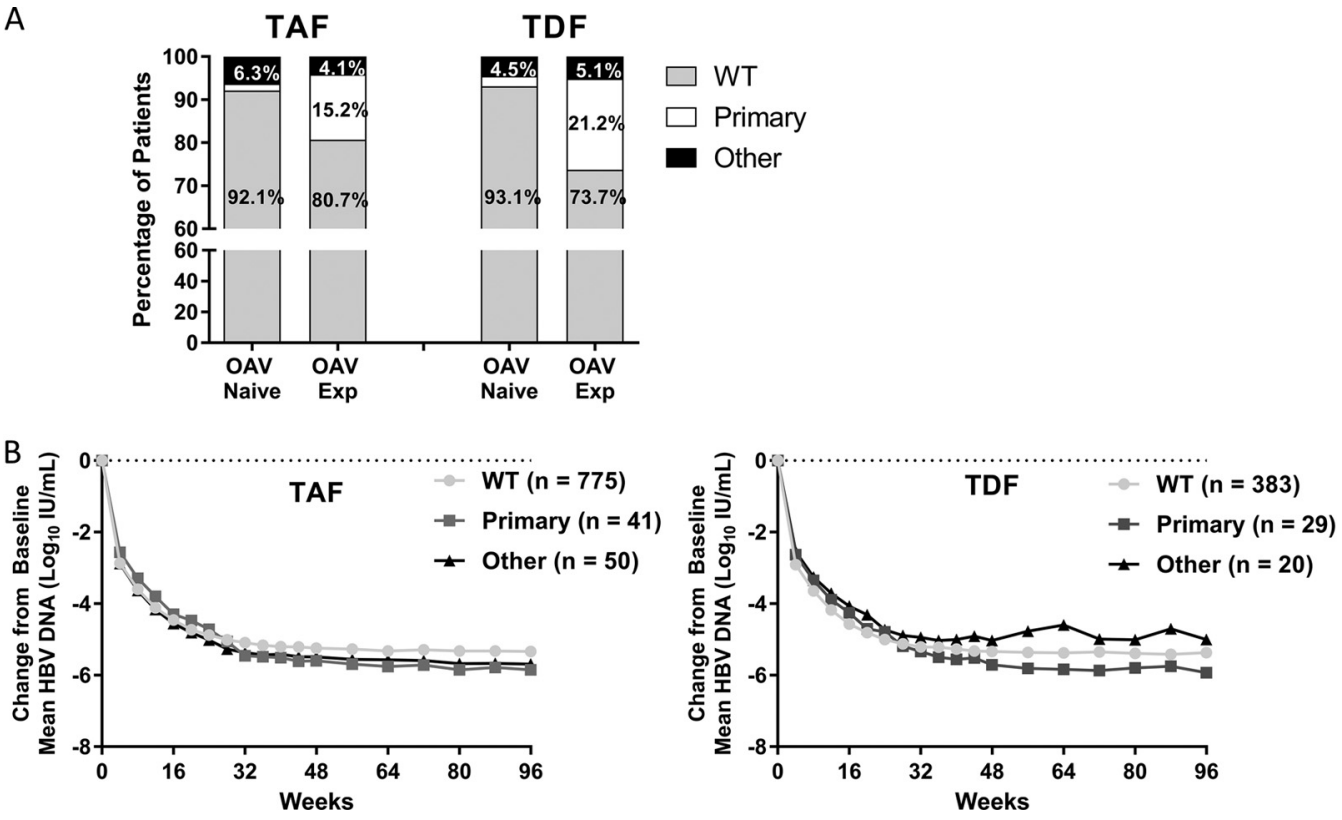

FIG 3 Baseline resistance surveillance and impact on treatment outcomes. (A) The percentage of patients with wild-type HBV (no resistance mutations detected at baseline), primary mutations, or other mutations (defined in methods) detected at baseline by INNO-LiPA in the TAF or TDF treatment group is depicted as a percentage of the group by baseline oral antiviral experience. (B) The mean change of HBV DNA from baseline for patients in the TAF (left) or TDF (right) treatment groups is shown for patients as determined by baseline resistance analysis.

conserved site substitutions detected at week 96 , only one conserved site substitution emerged in more than 1 patient (see Table S2 in the supplemental material). The rtA181T substitution was detected in 1 patient in the TAF group and 1 patient in the TDF group, as described below.

In addition to conserved site substitutions, the emergence of known resistance associated mutations was evaluated at week 96. The rtA181T substitution described above is an ADV-associated resistance mutation but has also been reported as emergent in patients with long-term LAM usage (22-24). One patient in the TAF group and one patient in the TDF group had emergence of rtA181T at week 96 (patients TAF 20 and TDF 10; see Table S2 in the supplemental material). The patient in the TDF group with rtA181T was OAV naive, while the patient in the TAF group was LAM experienced at baseline. The emergence of rtA181T was not associated with increases in plasma DNA in either patient, and both patients showed continual declines from baseline in

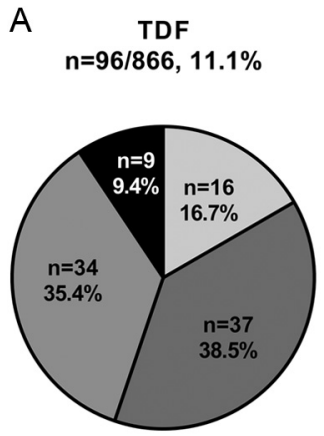

Conserved site changes

Polymorphic site changes

No change from BL

Unable to Sequence

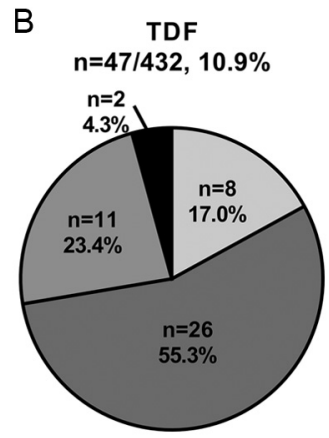

FIG 4 Sequence results for TAF and TDF patients who qualified for resistance analysis through week 96. Sequencing results for patients who qualified for sequencing during resistance surveillance through week 96 in the TAF (A) or TDF (B) are shown. The results are presented as amino acid changes from baseline. The number of patients in each analysis is noted as a percentage of the patients in the corresponding treatment group ( $n, \%)$. 
TABLE 1 Phenotypic analysis results for patients who experienced virologic breakthrough at week 96 while adherent to the study drug

\begin{tabular}{lll}
\hline Parameter & TAF & TDF \\
\hline $\begin{array}{l}\text { No. of patients phenotyped (\% of patients sequenced) } \\
\text { Virologic breakthrough without nonadherence }\end{array}$ & $18(19)$ & $7(15)$ \\
$\quad$ Conserved site changes & 13 & 7 \\
& 5 & 0.94 \\
Mean EC $_{50}$ fold change from baseline & 1.03 & $0.63-1.69$ \\
\hline
\end{tabular}

HBV DNA of $>6 \log _{10} \mathrm{IU} / \mathrm{ml}$ through week 96 in the absence of virologic breakthrough (see Fig. S1 in the supplemental material). In addition, the conserved site rtM180L substitution was detected in one patient. This is a reversion of the LAM-associated mutation toward the consensus amino acid (patient TAF 5; see Table S2 in the supplemental material). This patient was telbivudine and TDF experienced at baseline, and harbored the LAM- and ETV-associated rtL180M and rtM204I by INNO-LiPA, both of which reverted back to wild-type mixtures at week 96 (rtM180L/M and rt/204M/l). This patient was subjected to phenotypic analysis and remained sensitive to TAF, with a fold change value of 1.39 compared to baseline (Table 1).

An analysis of week 96 sequence results across both the TAF and TDF groups was conducted to determine whether emergent amino acid substitutions in the Pol/RT gene were observed in more than 1 patient. With the exception of rtA181T, no conserved amino acid substitutions were detected in more than one patient. Of the polymorphic site substitutions detected at week 96,13 substitutions were detected in more than one patient, three of which were reversions to a genotype A reference sequence (rtA38T, rtT118N, and rtN134D; GenBank accession number X02763 [25]). Of these 13 substitutions, only 4 were detected in more than two patients ( $r$ t16T, $n=3$; rtD134E, $n=4$; rtR138K, $n=3$; and rtV191I, $n=3$ ), with the remaining substitutions emergent in two patients each (rtA38T, rtS78T, rtS106C, rtT118N, rtD134E, rtS213T, rtN238H, rtM309K, and $\mathrm{rtC} 332 \mathrm{~S}$ ). These substitutions were detected among 18 patients in the TAF group and 7 patients in the TDF group. Of the 10 substitutions that were not a reversion to reference, 7 were included in the phenotypic analysis since these patients qualified for phenotyping due to virologic breakthrough (in the absence of nonadherence), and each showed no change in susceptibility to TAF or tenofovir (rtl16T, rtS78T, rtS106C, rtD134E, rtR138K, rtV191I, rtN238H; Table 1). Taken together, no pattern of emergent substitutions was detected through 96 weeks of treatment, and the majority of sequence changes are unique site changes.

Phenotypic analysis. To determine whether virologic breakthrough was accompanied by development of reduced susceptibility to study drugs, in vitro phenotypic evaluations were performed on patients that experienced virologic breakthrough while maintaining adherence to the study drug. In addition, patients with emergent conserved site substitutions rtP5L, rtN71Y, rtS116T, rtL260S, rtl265V, rtG295S, and rtK328M were subjected to phenotypic analysis. Patient isolates with the conserved site substitutions rtN71Y and rtS116T were unable to replicate and thus not included in the analysis. Patient with the rtS40A, rtC303S, and rtA181T substitutions were also not included in the analysis because patients with these sites present at baseline suppressed virus (rtS40A, $n=1$ patient in the present study), or the substitution has been previously subjected to phenotypic analyses and found to remain sensitive to TFV (rtC303S, study GS-US-174-0102, unpublished results; rtA181T, [26]). Sensitivity to TAF was measured for patients in the TAF group, but since TDF is unstable in the culture medium due to the presence of serum esterases, TFV was used to determine sensitivity to TDF for patients in the TDF group (27). Phenotypic analysis of the baseline and postbaseline isolates was performed in a total of 25 patients: 18 patients in the TAF group and 7 TDF-treated patients (Table 1). All postbaseline virus pools and clones tested remained sensitive with a fold change from baseline of $<2$-fold, which was 
within the variability of the assay (mean $50 \%$ effective concentration $\left[\mathrm{EC}_{50}\right]$ fold changes from the baseline of 1.01 and 0.94 , respectively).

\section{DISCUSSION}

Tenofovir alafenamide is a novel prodrug of tenofovir with enhanced plasma stability compared to TDF, resulting in an improved safety profile compared to TDF in regard to bone and renal parameters while demonstrating similar efficacy through 2 years $(96$ weeks) $(18,28)$. Importantly, both prodrugs share the same pharmacologically active moiety (TFV-diphosphate) within hepatocytes infected with $\operatorname{HBV}(29,30)$. Becuase TAF is now approved for the treatment of adults with $\mathrm{CHB}$ and compensated liver disease in the United States, Europe, Japan, and several other countries worldwide, it is essential that its resistance profile be characterized, particularly in comparison to that of TDF, which has not shown resistance development in CHB patients through 8 years of use (31). This study represents the first comprehensive resistance analysis conducted from two, large ongoing phase 3 trials evaluating TAF versus TDF in the treatment of $\mathrm{CHB}$ in treatment-naive and -experienced patients. At baseline, patient demographic, disease, and viral characteristics were similar across treatment groups in both $\mathrm{HBeAg}$ positive and HBeAg-negative patients.

The patient populations included in the studies were representative of global CHB patients and included treatment-naive and treatment-experienced patients infected with HBV genotypes A through D. Through week 96, no differences in treatment response were observed between TAF and TDF regardless of the baseline genotype. In addition, TAF and TDF demonstrated similar efficacies, including patients with known resistance mutations at baseline which were detected at a higher rate in treatmentexperienced patients. This finding is consistent with previous studies evaluating TDF in patients with LAM or ADV resistance mutations which demonstrated that viral suppression was achieved and maintained in patients having a poor response to other antivirals, including those with documented baseline mutations (32-35). In patients with LAM-R at baseline, a higher baseline viral load was associated with persistent viremia through week 96 (33), indicating that the baseline viral load, as opposed to baseline viral resistance, is what predominantly contributes to delays in the suppression of HBV DNA in patients treated with TDF. The high rates of viral suppression achieved with TDF and TAF are reflective of the prior results in which HBV encoding for resistance mutations to ADV, LAM, or ETV retain sensitivity to tenofovir in vitro (26).

At week 96 , the majority of patients in this analysis that did not suppress HBV DNA were persistently viremic in the absence of breakthrough. Viremia in the absence of breakthrough indicates patients may require a longer duration of treatment to achieve complete viral suppression HBV DNA, particularly in patients with higher viral loads at baseline. This is consistent with published work demonstrating that in some TDFtreated patients suppression rates increase with longer treatment durations $(9,10,36)$. In line with this, patients in this study did achieve higher suppression rates at week 96 compared to week 48 (16-18), particularly for those who were HBeAg positive. Patients who experience virologic breakthrough often present more of a concern for the development of antiviral drug resistance. In the present study, a small and similar proportion of patients experienced confirmed virologic breakthrough in both treatment groups $(<3 \%)$. Previous studies with TDF monotherapy demonstrated comparable results to the present study, with $2.3 \%(10 / 426)$ of patients experiencing virologic breakthrough on TDF through week 48 (37). In the present study, 14 of 38 (36.8\%) patients who experience virologic breakthrough at week 96 had breakthrough associated with undetectable levels of tenofovir in the plasma, which is consistent with previous studies demonstrating a high degree of nonadherence among patients who experience virologic breakthrough $(9,10,38)$. Phenotypic analysis of patients with virologic breakthrough in the absence of nonadherence, as determined by plasma drug levels, showed these patients to have no change in sensitivity to tenofovir in vitro. Thus, the low rates of virologic breakthrough, often associated with nonadherence, and the lack of phenotypic resistance in postbase- 
line isolates suggest that virologic breakthrough is not associated with clinical resistance in this study. Previous long-term experience with TDF treatment suggests that virologic breakthrough associated with nonadherence is transient, and patients resuppress with the resumption of therapy $(9,10)$.

A relatively small percentage of enrolled patients qualified for sequence analysis having HBV DNA levels of $\geq 69 \mathrm{lU} / \mathrm{ml}$ at week 96 (11.0\%). The majority of these patients either had no change from their baseline sequence or were unable to be sequenced (60.8\% of patients sequenced overall), while the majority of emergent substitutions were unique (58 of the 92 substitutions detected). Few of the amino acid site substitutions detected at week 96 were observed to develop in multiple patients. Of those detected in more than one patient, all but one (rtA181T) were at polymorphic sites. The polymorphic rtS78T substitutions has been previously reported to develop in two patients who did not achieve suppression during TDF treatment, with corresponding $\mathrm{EC}_{50}$ fold changes of $<2$-fold (39). Two patients in the present study developed rtS78T at week 96. Of these, one was subjected to phenotypic analysis, with the rtS78T substitutions conferring no reduction in susceptibility to TAF. Both patients had rtS78T present in a mixture with wild type (rtS78S/T), and one patient had intermittent drug compliance through 96 weeks. Three additional patients developed rtS78T at week 48 but went on to suppress HBV DNA by week 96 with additional treatment (data not shown). In this study, the emergence of rtA181T occurred in one patient in each treatment group at week 96 . The patient in the TAF group was LAM experienced when they entered the study. Although rtA181T is a known ADV resistance mutation, rtA181T has been reported to emerge in patients during long-term LAM treatment (22-24). Both patients had continual declines in HBV DNA levels from baseline through week 96 with no increase in HBV DNA associated with the detection of rtA181T. This substitution is a known adefovir resistance mutation that remains sensitive to TAF and tenofovir in in vitro phenotypic assays (26). Similarly, patients with suboptimal response to $\operatorname{ADV}$ treatment $(34,40)$ or patients with known rtA181V/T substitutions at baseline (33) can maintain HBV DNA suppression on TDF treatment.

In summary, results from extensive sequence analyses and phenotypic assays in patients with virologic breakthrough demonstrate that no TAF-associated resistance substitutions associated with sustained virologic breakthrough have been identified through 96 weeks of treatment. These results support a high barrier to resistance to TAF, as has been previously demonstrated with TDF, both of which are prodrugs of TFV. Overall, we demonstrate here that TAF monotherapy achieved high levels of viral suppression over 96 weeks of treatment and that no resistance to TAF developed in patients with $\mathrm{CHB}$.

\section{MATERIALS AND METHODS}

The study designs for these clinical trials (GS-US-320-0108 [study 108] and GS-US-320-0110 [study 110]) have been previously described (16-18). The studies were conducted in compliance with all regulatory obligations and the Institutional Review Board and informed consent regulations at each investigational site. Briefly, patients were randomized 2:1 to receive TAF or TDF for up to 144 weeks, followed by the option of open-label TAF treatment for up to week 384. The design of each trial is identical except for the HBeAg status for enrollment, with study 108 enrolling HBeAg-negative patients and study 110 enrolling HBeAg-positive patients. Both treatment-naive and treatment-experienced patients were enrolled, with "treatment naive" being defined as $<12$ weeks of prior OAV treatment and "treatment experienced" being defined as $\geq 12$ weeks of prior OAV treatment. Results through week 96 are reported here.

Sequence analysis. At baseline, HBV genotype was determined using an INNO-LiPA HBV genotyping assay (Innogenetics, Ghent, Belgium). The presence of known antiviral resistance mutations was detected at baseline using the INNO-LiPA Multi-DR v2/v3 assay (Innogenetics). The INNO-LiPA Multi-DR v2/v3 assay detects variants present at amino acid positions rtL80, rtV173, rtL180, rtA181, rtT184, rtA194, rtS202, rtM204, rtN236, and rtM250. Mutations detected were then assigned to a resistance category based on available in vitro phenotypic data. Mutations that confer reduced susceptibility to $\mathrm{CHB}$ treatment in vitro were classified as primary resistance mutations, including LAM-R (rtM204V/I/S), ADV-R (rtA181T/N, rtN236T), and ETV-R (rtM204V/I \pm rtT184X \pm rtS202X \pm rtM250X) (41-48). Remaining mutations detected by INNO-LiPA Multi-DR v2/v3 considered to be compensatory mutations or unknown variants at resistance-associated positions were classified as other mutations.

Resistance surveillance was conducted at week 96. Sequencing of the HBV Pol/RT was attempted on serum samples for any patient with viremia at week 96 (HBV DNA $\geq 69 \mathrm{IU} / \mathrm{ml}$ ) or at the time of early 
discontinuation with at least 24 weeks or treatment. Samples with HBV DNA levels of $<69 \mathrm{IU} / \mathrm{ml}$ were not included in the analysis by sequencing due to assay limitations. DNA was isolated from $200 \mu \mathrm{l}$ of patient serum using an automated MagNA Pure System (Roche, Basel, Switzerland). The HBV Pol/RT domain (amino acids 1 to 344) was amplified using the Expand High Fidelity PCR system (Roche). Amplified PCR products were purified using Ampure XP beads (Beckman Coulter, Brea, CA) prior to quantification using Quant-iT PicoGreen dsDNA kit (Life Technologies, Carlsbad, CA). For patients with HBV DNA levels of $\leq 159 \mathrm{IU} / \mathrm{ml}$, population dideoxy sequencing was performed using the ABI BigDye Terminator v3.1 cycle sequencing kit (Thermo Fisher Scientific, Waltham, MA). For patients with HBV DNA levels of $>159 \mathrm{IU} / \mathrm{ml}$, PCR products were deep sequenced using the lllumina-MiSeq platform (150-base paired-end reads; Illumina, Inc., San Diego, CA). Deep or population sequencing was performed on patient baseline samples. Baseline consensus sequence was used to align the raw reads of corresponding postbaseline samples using MOSAIK (Boston College, USA). For samples with deep-sequencing data available, the raw reads were assembled using VICUNA (49) to create an assembly sequence (Broad Institute, USA) and then aligned to the assembly sequence. Amino acid substitutions were analyzed with a mutation frequency cutoff of $15 \%$ and compared to the respective baseline sequence for each patient. All amplification and sequencing steps were performed at DDL Diagnostic Laboratories (Rijswijk, Netherlands). A resolution of an amino acid mixture at baseline to a full call amino acid in the corresponding postbaseline sequence was not included as a change from baseline.

Polymorphic and conserved amino acids have been previously described (9). Conserved sites were defined as sites having one amino acid present or having two amino acids present with one amino acid observed at $>99 \%$. All other positions were classified as polymorphic.

Phenotypic analysis. The in vitro susceptibility to TAF or tenofovir was assessed for any patient with virologic breakthrough with no evidence of nonadherence and for patients with conserved site substitutions detected. Virologic breakthrough was defined as confirmed an HBV DNA level of $\geq 69 \mathrm{IU} / \mathrm{ml}$ after having $<69 \mathrm{IU} / \mathrm{ml}$ or a $\geq 1.0-\log _{10}$ increase in HBV DNA from nadir. Phenotypic analyses were performed as previously described with some modifications (50). Briefly, the HBV Pol/RT PCR product generated for sequencing was ligated into a plasmid vector (pRTAN) expressing the full genotype A HBV genome lacking the RT region $(21,51)$. Recombinant plasmids were transiently transfected into HepG2 cells and HBV DNA in the supernatant was measured using QuantiGene 2.0 branched DNA technology with HBV specific probes (Affymetrix, Santa Clara, CA). $\mathrm{EC}_{50}$ s were calculated with respect to the assay reference. Fold changes in the $\mathrm{EC}_{50}$ were determined by comparing the fold change from reference of the baseline sample to the fold change from reference of the on-treatment sample. Sensitivity to TAF was measured for patients in the TAF group. For patients in the TDF group, sensitivity to tenofovir was evaluated as TDF is unstable in cell culture medium due to the presence of serum esterases (27). A wild-type laboratory virus (pHY92) and an ADV-resistant virus (rtA181V + rtN236T) were used as controls for sensitivity and resistance, respectively.

Adherence to study medication. Adherence to the study drug was measured by determining tenofovir levels in the plasma using liquid chromatography/mass spectrometry as previously described (9). Nonadherence was defined as tenofovir levels below the limit of quantitation or tenofovir trough levels more than 10 times below the average level with TDF at $300 \mathrm{mg}$ once daily $(<1 \mathrm{ng} / \mathrm{ml})$.

\section{SUPPLEMENTAL MATERIAL}

Supplemental material for this article may be found at https://doi.org/10.1128/AAC .01064-18.

SUPPLEMENTAL FILE S1, PDF file, $0.1 \mathrm{MB}$.

\section{ACKNOWLEDGMENTS}

We thank Becket Feierbach, Evguenia S. Svarovskaia, and Hongmei Mo for editorial review of the manuscript.

This study was sponsored and financially supported by Gilead Sciences, Inc. Andrea L. Cathcart, Neeru Bhardwaj, Yang Liu, Ross Martin, Silvia Chang, Stephanie Cox, Bandita Parhy, Eric Zhou, John F. Flaherty, Anuj Gaggar, and Kathryn M. Kitrinos were employed by and own stock in Gilead Sciences, Inc. Calvin Q. Pan has received research grants from Gilead, Bristol Myers Squibb, and Merck and also serves as a consultant or advisor for Gilead and the speakers' bureau for Gilead, Abbvie, and Intercept. Namiki Izumi received lecture fee from Gilead Science, AbbVie, and Bayer. Maria Buti has served as an advisor for Gilead, Abbvie, and Merck.

Andrea L. Cathcart, Neeru Bhardwaj, Yang Liu, Stephanie Cox, Bandita Parhy, Eric Zhou, Ross Martin, Silvia Chang, Lanjia Lin, and Katie Kitrinos were involved in study concept and design, acquisition, analysis, and interpretation of data. John F. Flaherty and Anuj Gaggar were involved in study concept and design and critical revision of the manuscript. Henry Lik-Yuen Chan, Patrick Marcellin, Calvin Q. Pan, Shalimar, Maria Buti, Namiki Izumi, and Young-Suk Lim were involved in study support, study supervision, and intellectual contributions. 


\section{REFERENCES}

1. Schweitzer A, Horn J, Mikolajczyk RT, Krause G, Ott JJ. 2015. Estimations of worldwide prevalence of chronic hepatitis B virus infection: a systematic review of data published between 1965 and 2013. Lancet 386: 1546-1555. https://doi.org/10.1016/S0140-6736(15)61412-X.

2. Lok ASF, Lai C-L, Leung N, Yao G-B, Cui Z-Y, Schiff ER, Dienstag JL, Heathcote EJ, Little NR, Griffiths DA, Gardner SD, Castiglia M. 2003. Long-term safety of lamivudine treatment in patients with chronic hepatitis B. Gastroenterology 125:1714-1722. https://doi.org/10.1053/j .gastro.2003.09.033.

3. Angus $P$, Vaughan $R$, Xiong $S$, Yang $H$, Delaney W, Gibbs $C$, Brosgart $C$, Colledge D, Edwards R, Ayres A, Bartholomeusz A, Locarnini S. 2003. Resistance to adefovir dipivoxil therapy associated with the selection of a novel mutation in the HBV polymerase. Gastroenterology 125:292-297. https://doi.org/10.1016/S0016-5085(03)00939-9.

4. Hadziyannis SJ, Tassopoulos NC, Heathcote EJ, Chang TT, Kitis G, Rizzetto M, Marcellin P, Lim SG, Goodman Z, Ma J, Brosgart CL, Borroto-Esoda K, Arterburn S, Chuck SL. 2006. Long-term therapy with adefovir dipivoxil for $\mathrm{HBeAg-negative} \mathrm{chronic} \mathrm{hepatitis} \mathrm{B} \mathrm{for} \mathrm{up} \mathrm{to} 5$ years. Gastroenterology 131:1743-1751. https://doi.org/10.1053/j.gastro.2006.09.020.

5. Liaw YF, Gane E, Leung N, Zeuzem S, Wang Y, Lai CL, Heathcote EJ, Manns M, Bzowej N, Niu J, Han SH, Hwang SG, Cakaloglu Y, Tong MJ, Papatheodoridis G, Chen Y, Brown NA, Albanis E, Galil K, Naoumov NV. 2009. 2-year GLOBE trial results: telbivudine Is superior to lamivudine in patients with chronic hepatitis B. Gastroenterology 136:486-495. https://doi.org/10.1053/ j.gastro.2008.10.026.

6. Colonno RJ, Rose R, Baldick CJ, Levine S, Pokornowski K, Yu CF, Walsh A, Fang J, Hsu M, Mazzucco C, Eggers B, Zhang S, Plym M, Klesczewski K, Tenney DJ. 2006. Entecavir resistance is rare in nucleoside naive patients with hepatitis B. Hepatology 44:1656-1665. https://doi.org/10.1002/hep .21422.

7. Tenney DJ, Rose RE, Baldick CJ, Pokornowski KA, Eggers BJ, Fang J, Wichroski MJ, Xu D, Yang J, Wilber RB, Colonno RJ. 2009. Long-term monitoring shows hepatitis $B$ virus resistance to entecavir in nucleosidenaive patients is rare through 5 years of therapy. Hepatology 49: 1503-1514. https://doi.org/10.1002/hep.22841.

8. Zoulim F, Locarnini S. 2009. Hepatitis B virus resistance to nucleos(t)ide analogues. Gastroenterology 137:1593-1608. https://doi.org/10.1053/j gastro.2009.08.063.

9. Kitrinos KM, Corsa A, Liu Y, Flaherty J, Snow-Lampart A, Marcellin P, Borroto-Esoda K, Miller MD. 2014. No detectable resistance to tenofovir disoproxil fumarate after 6 years of therapy in patients with chronic hepatitis B. Hepatology 59:434-442. https://doi.org/10.1002/hep.26686.

10. Liu Y, Corsa AC, Buti M, Cathcart A, Flaherty JF, Miller MD, Kitrinos K, Marcellin P, Gane E. 2016. No detectable resistance to tenofovir disoproxil fumarate in $\mathrm{HBeAg}^{+}$and $\mathrm{HBeAg}^{-}$patients with chronic hepatitis B after 8 years of treatment. J Viral Hepatitis 24:68-74. https://doi.org/ $10.1111 /$ jvh.12613.

11. Delaney WE, Ray IVAS, Yang H, Qi X, Xiong S, Zhu Y, Miller MD. 2006 Intracellular metabolism and in vitro activity of tenofovir against hepatitis B virus. Antimicrob Agents Chemother 50:2471-2477. https://doi .org/10.1128/AAC.00138-06.

12. Marcellin $P$, Gane EJ, Flisiak R, Trinh HN, Petersen J, Gurel S, Kaita KD, Kotzev IA, Tsai N, Flaherty JF, Schall REA, Kitrinos K, Subramanian M, McHutchison JG, George J, Janssen HL, Buti M. 2014. Long-term treatment with tenofovir disoproxil fumarate for chronic hepatitis B infection is safe and well tolerated and associated with durable virologic response with no detectable resistance: 8-year results from two phase 3 trials, abstr. 55th Annu Meet Am Assoc Study Liver Dis, Boston, MA.

13. Fung $S$, Kwan $P$, Fabri $M$, Horban $A$, Pelemis $M$, Hann HW, Gurel $S$, Caruntu FA, Flaherty JF, Massetto B, Dinh P, Corsa A, Subramanian GM, McHutchison JG, Husa P, Gane E. 2014. Randomized comparison of tenofovir disoproxil fumarate versus emtricitabine and tenofovir disoproxil fumarate in patients with lamivudine-resistant chronic hepatitis $B$. Gastroenterology 146:980-988. https://doi.org/10.1053/j.gastro.2013.12 .028 .

14. Gilead Sciences, Inc. 2017. Vemlidy (tenofovir alafenamide) tablets, for oral use. U.S. prescribing information. Gilead Sciences, Inc, Foster City, CA.

15. Sax PE, Wohl D, Yin MT, Post F, DeJesus E, Saag M, Pozniak A, Thompson M, Podzamczer D, Molina JM, Oka S, Koenig E, Trottier B, AndradeVillanueva J, Crofoot G, Custodio JM, Plummer A, Zhong L, Cao H, Martin
H, Callebaut C, Cheng AK, Fordyce MW, McCallister S, Team G-U-S. 2015. Tenofovir alafenamide versus tenofovir disoproxil fumarate, coformulated with elvitegravir, cobicistat, and emtricitabine, for initial treatment of HIV-1 infection: two randomised, double-blind, phase 3, noninferiority trials. Lancet 385:2606-2615. https://doi.org/10.1016/S0140 -6736(15)60616-X.

16. Buti M, Gane E, Seto WK, Chan HLY, Chuang WL, Stepanova T, Hui AJ, Lim YS, Mehta R, Janssen HLA, Acharya SK, Flaherty JF, Massetto B, Cathcart AL, Kim K, Gaggar A, Subramanian GM, McHutchinson JG, Pan CQ, Brunetto M, Izumi N, Marcellin P. 2016. Tenofovir alafenamide versus tenofovir disoproxil fumarate for the treatment of patients with $\mathrm{HBeAg}$ negative chronic hepatitis B virus infection: a randomised, double-blind, phase 3, non-inferiority trial. Lancet Gastroenterol Hepatol 1:196-206. https://doi.org/10.1016/S2468-1253(16)30107-8.

17. Chan HLY, Fung $S$, Seto WK, Chuang WL, Chen CY, Kim HJ, Hui AJ, Janssen HLA, Chowdhury A, Tsang TYO, Mehta R, Gane E, Flaherty JF, Massetto B, Gaggar A, Kitrinos KM, Lin L, Subramanian GM, McHutchison JG, Lim YS, Acharya SK, Agarwal K. 2016. Tenofovir alafenamide versus tenofovir disoproxil fumarate for the treatment of $\mathrm{HBeAg}$-positive chronic hepatitis B virus infection: a randomised, double-blind, phase 3 , non-inferiority trial. Lancet Gastroenterol Hepatol 1:185-195. https://doi .org/10.1016/S2468-1253(16)30024-3.

18. Agarwal K, Fung S, Seto WK, Lim YS, Gane E, Janssen HLA, Sharma M, Chuang WL, Bae H, Yoon KT, Flaherty JF, Lau A, Gaggar A, Suri V, Cathcart A, Lin L, Subramanian GM, Shalimar, Furusyo N, Buti M, Chan LY. 2017. A phase 3 study comparing tenofovir alafenamide to tenofovir disoproxil fumarate in patients with $\mathrm{HBeAg}$-positive, chronic hepatitis B: efficacy and safety results at week 96, poster FRI-153. Int Liver Cong 2017. European Association for the Study of the Liver, Amsterdam, Netherlands.

19. Wohl D, Oka S, Clumeck N, Clarke A, Brinson C, Stephens J, Tashima K, Arribas JR, Rashbaum B, Cheret A, Brunetta J, Mussini C, Tebas P, Sax PE, Cheng A, Zhong L, Callebaut C, Das M, Fordyce M, Gs US, Study T. 2016. Brief report: a randomized, double-blind comparison of tenofovir alafenamide versus tenofovir disoproxil fumarate, each coformulated with elvitegravir, cobicistat, and emtricitabine for initial HIV-1 treatment: week 96 results. J Acquir Immune Defic Syndr 72:58-64. https://doi.org/ 10.1097/QAI.0000000000000940.

20. Palumbo E. 2007. Hepatitis B genotypes and response to antiviral therapy: a review. Am J Ther 14:306-309. https://doi.org/10.1097/01 .pap.0000249927.67907.eb.

21. Degertekin B, Hussain M, Tan J, Oberhelman K, Lok AS. 2009. Sensitivity and accuracy of an updated line probe assay (HBV DR v.3) in detecting mutations associated with hepatitis B antiviral resistance. J Hepatol 50:42-48. https://doi.org/10.1016/j.jhep.2008.08.020.

22. Yeh CT, Chien RN, Chu C, Liaw Y. 2000. Clearance of the original hepatitis $B$ virus YMDD-motif mutants with emergence of distinct lamivudineresistant mutants during prolonged lamivudine therapy. Hepatology 31:1318-1326. https://doi.org/10.1053/jhep.2000.7296.

23. Yatsuji H, Noguchi C, Hiraga N, Mori N, Tsuge M, Imamura M, Takahashi S, Takahashi S, Iwao E, Fujimoto Y, Ochi H, Abe H, Maekawa T, Tateno C, Yoshizato K, Suzuki F, Kumada H, Chayama K. 2006. Emergence of a novel lamivudine-resistant hepatitis $B$ virus variant with a substitution outside the YMDD motif. Antimicrob Agents Chemother 50:3867-3874. https://doi.org/10.1128/AAC.00239-06.

24. Villet S, Pichoud C, Billioud G, Barraud L, Durantel S, Trepo C, Zoulim F. 2008. Impact of hepatitis $B$ virus rtA181V/T mutants on hepatitis $B$ treatment failure. J Hepatol 48:747-755. https://doi.org/10.1016/j.jhep .2008.01.027.

25. Hayer J, Jadeau F, Deleage G, Kay A, Zoulim F, Combet C. 2013. HBVdb: a knowledge database for hepatitis B virus. Nucleic Acids Res 41: D566-D570. https://doi.org/10.1093/nar/gks1022.

26. Liu Y, Miller MD, Kitrinos KM. 2017. Tenofovir alafenamide demonstrates broad cross-genotype activity against wild-type HBV clinical isolates and maintains susceptibility to drug-resistant HBV isolates in vitro. Antiviral Res 139:25-31. https://doi.org/10.1016/j.antiviral.2016.12.012.

27. Callebaut C, Stepan G, Tian Y, Miller MD. 2015. In vitro virology profile of tenofovir alafenamide, a novel oral prodrug of tenofovir with improved antiviral activity compared to that of tenofovir disoproxil fumarate. Antimicrob Agents Chemother 59:5909-5916. https://doi.org/10.1128/ AAC.01152-15. 
28. Brunetto M, Lim YS, Gane E, Seto WK, Osipenko M, Ahn SH, Janssen HLA, Shukla A, Chuang WL, Trinh H, Celen MK, Flaherty JF, Lau AH, Gaggar A, Suri V, Bhardwaj N, Kim K, Subramanian GM, Pan C, Izumi N, Marcellin P, Chan HLY, Buti M. 2017. A phase 3 study comparing tenofovir alafenamide (TAF) to tenofovir disoproxil fumarate (TDF) in patients with HBeAg-negative, chronic hepatitis B (CHB): efficacy and safety results at week 96, presentation. Int Liver Cong 2017. European Association for the Study of the Liver, Amsterdam, Netherlands.

29. Babusis D, Phan TK, Lee WA, Watkins WJ, Ray AS. 2013. Mechanism for effective lymphoid cell and tissue loading following oral administration of nucleotide prodrug GS-7340. Mol Pharm 10:459-466. https://doi.org/ $10.1021 / \mathrm{mp} 3002045$.

30. Murakami E, Wang T, Park Y, Hao J, Lepist El, Babusis D, Ray AS. 2015. Implications of efficient hepatic delivery by tenofovir alafenamide (GS7340) for hepatitis B virus therapy. Antimicrob Agents Chemother 59: 3563-3569. https://doi.org/10.1128/AAC.00128-15.

31. Liu Y, Corsa AC, Buti M, Cathcart AL, Flaherty JF, Miller MD, Kitrinos KM, Marcellin P, Gane EJ. 2017. No detectable resistance to tenofovir disoproxil fumarate in $\mathrm{HBeAg}^{+}$and $\mathrm{HBeAg}^{-}$patients with chronic hepatitis B after 8 years of treatment. J Viral Hepat 24:68-74. https://doi.org/10 $.1111 /$ jvh.12613.

32. Patterson SJ, George J, Strasser SI, Lee AU, Sievert W, Nicoll AJ, Desmond PV, Roberts SK, Locarnini S, Bowden S, Angus PW. 2011. Tenofovir disoproxil fumarate rescue therapy following failure of both lamivudine and adefovir dipivoxil in chronic hepatitis B Gut 60:247-254. https://doi .org/10.1136/gut.2010.223206.

33. Corsa AC, Liu Y, Flaherty JF, Mitchell B, Fung SK, Gane E, Miller MD, Kitrinos KM. 2014. No resistance to tenofovir disoproxil fumarate through 96 weeks of treatment in patients with lamivudine-resistant chronic hepatitis B. Clin Gastroenterol Hepatol 12:2106-2112. https:// doi.org/10.1016/j.cgh.2014.05.024.

34. Berg T, Zoulim F, Moeller B, Trinh H, Marcellin P, Chan S, Kitrinos KM, Dinh P, Flaherty JF, Jr, McHutchison JG, Manns M. 2014. Long-term efficacy and safety of emtricitabine plus tenofovir DF versus tenofovir DF monotherapy in adefovir-experienced chronic hepatitis B patients. J Hepatol 60:715-722. https://doi.org/10.1016/j.jhep.2013.11.024.

35. Fung S, Kwan P, Fabri M, Horban A, Pelemis M, Hann HW, Gurel S, Caruntu FA, Flaherty JF, Massetto B, Kim K, Kitrinos KM, Subramanian GM, McHutchison JG, Yee LJ, Elkhashab M, Berg T, Sporea I, Yurdaydin C, Husa P, Jablkowski MS, Gane E. 2017. Tenofovir disoproxil fumarate (TDF) versus emtricitabine (FTC)/TDF in lamivudine-resistant hepatitis B: a 5-year randomised study. J Hepatol 66:11-18. https://doi.org/10.1016/ j.jhep.2016.08.008.

36. Gordon SC, Krastev Z, Horban A, Petersen J, Sperl J, Dinh P, Martins EB, Yee LJ, Flaherty JF, Kitrinos KM, Rustgi VK, Marcellin P. 2013. Efficacy of tenofovir disoproxil fumarate at 240 weeks in patients with chronic hepatitis B with high baseline viral load. Hepatology 58:505-513. https:// doi.org/10.1002/hep.26277.

37. Marcellin P, Heathcote E, Buti M, Gane E, de Man RA, Krastev Z, Germanidis G, Lee SS, Flisiak R, Kaita K, Manns M, Kotzev I, Tchernev K, Buggisch $P$, Weilert F, Kurdas OO, Shiffman ML, Trinh $H$, Washington MK, Sorbel J, Anderson J, Snow-Lampart A, Mondou E, Quinn J, Rousseau F. 2008. Tenofovir disoproxil fumarate versus adefovir dipivoxil for chronic hepatitis B. N Engl J Med 359:2442-2455. https://doi.org/10.1056/ NEJMoa0802878.

38. Hongthanakorn C, Chotiyaputta W, Oberhelman K, Fontana RJ, Marrero JA, Licari T, Lok AS. 2011. Virological breakthrough and resistance in patients with chronic hepatitis $B$ receiving nucleos(t)ide analogues in clinical practice. Hepatology 53:1854-1863. https://doi.org/10.1002/hep .24318 .

39. Shirvani-Dastgerdi E, Winer BY, Celia-Terrassa T, Kang Y, Tabernero D, Yagmur E, Rodriguez-Frias F, Gregori J, Luedde T, Trautwein C, Ploss A, Tacke F. 2017. Selection of the highly replicative and partially multidrug resistant rtS78T HBV polymerase mutation during TDF-ETV COMBINATION THERapy. J Hepatol 67:246-254. https://doi.org/10 .1016/j.jhep.2017.03.027.

40. van Bommel $F$, de Man RA, Wedemeyer $H$, Deterding $K$, Petersen J, Buggisch P, Erhardt A, Huppe D, Stein K, Trojan J, Sarrazin C, Bocher WO, Spengler U, Wasmuth HE, Reinders JG, Moller B, Rhode P, Feucht HH, Wiedenmann B, Berg T. 2010. Long-term efficacy of tenofovir monotherapy for hepatitis B virus-monoinfected patients after failure of nucleoside/nucleotide analogues. Hepatology 51:73-80. https://doi.org/ 10.1002/hep.23246.

41. ViiV Healthcare. 2011. Epivir (lamivudine) tablets and oral solution. US highlights of prescribing information. ViiV Healthcare, Brentford, United Kingdom.

42. Gilead Sciences, Inc. 2012. Hepsera (adefovir dipivoxil) tablets, for oral use. US prescribing information. Gilead Sciences, Inc., Foster City, CA.

43. Bristol-Myers Squibb Pharmaceutical, Ltd. 2014. Baraclude $0.5 \mathrm{mg}$ and $1.0 \mathrm{mg}$ film-coated tablets: summary of product characteristics. BristolMyers Squibb Pharmaceuticals, Ltd., London, United Kingdom.

44. Warner N, Locarnini S, Kuiper M, Bartholomeusz A, Ayres A, Yuen L, Shaw T. 2007. The L80l substitution in the reverse transcriptase domain of the hepatitis B virus polymerase is associated with lamivudine resistance and enhanced viral replication in vitro. Antimicrob Agents Chemother 51:2285-2292. https://doi.org/10.1128/AAC.01499-06.

45. Fung SK, Mazzulli T, Sherman M, Popovic V. 2009. Tenofovir (TDF) is effective in lamivudine (LAM)-resistant chronic hepatitis B patients who harbor rtA194T at baseline, poster 399. 60th Annu Meet Am Assoc Study Liver Dis, Boston, MA.

46. Ono SK, Kato N, Shiratori Y, Kato J, Goto T, Schinazi RF, Carrilho FJ, Omata M. 2001. The polymerase L528M mutation cooperates with nucleotide binding-site mutations, increasing hepatitis $\mathrm{B}$ virus replication and drug resistance. J Clinical Invest 107:449-455. https://doi .org/10.1172/JCI11100.

47. Delaney WE, Yang IVH, Westland CE, Das K, Arnold E, Gibbs CS, Miller MD, Xiong S. 2003. The hepatitis B virus polymerase mutation rtV173L is selected during lamivudine therapy and enhances viral replication in vitro. J Virol 77:11833-11841. https://doi.org/10.1128/JVI.77.21.11833 -11841.2003 .

48. Zoulim F, Locarnini S. 2013. Optimal management of chronic hepatitis B patients with treatment failure and antiviral drug resistance. Liver Int 33(Suppl 1):S116-S124. https://doi.org/10.1111/liv.12069.

49. Yang X, Charlebois P, Gnerre S, Coole MG, Lennon NJ, Levin JZ, Qu J, Ryan EM, Zody MC, Henn MR. 2012. De novo assembly of highly diverse viral populations. BMC Genomics 13:475. https://doi.org/10.1186/1471 $-2164-13-475$.

50. Liu Y, Kitrinos KM. 2013. In vitro phenotyping of recombinant hepatitis $B$ virus containing the polymerase/reverse transcriptase gene from clinical isolates, vol 1030, p 1-19. In Gong EY (ed), Antiviral methods and protocols: methods in molecular biology. Humana Press, Totowa, NJ.

51. Zhu Y, Curtis M, Borroto-Esoda K. 2011. HBV DNA replication mediated by cloned patient HBV reverse transcriptase genes from HBV genotypes $\mathrm{A}-\mathrm{H}$ and its use in antiviral phenotyping assays. J Virol Methods 173: 340-346. https://doi.org/10.1016/j.jviromet.2011.03.006. 